\title{
Mechanisms of Endothelial Regeneration and Vascular Repair and Their Application to Regenerative Medicine
}

\author{
Colin E. Evans, ${ }^{* \dagger}$ M. Luisa Iruela-Arispe, ${ }^{\ddagger \S}$ and You-Yang Zhao ${ }^{* \$ \delta \uparrow \|}$
}

From the Program for Lung and Vascular Biology and Section of Injury Repair and Regeneration,* Stanley Manne Children's Research Institute, Ann \& Robert H. Lurie Children's Hospital of Chicago, Chicago; and the Division of Critical Care, ${ }^{\dagger}$ Department of Pediatrics, the Department of Cell and Developmental Biology, ${ }^{\ddagger}$ the Feinberg Cardiovascular and Renal Research Institute, ${ }^{\S}$ the Division of Pulmonary and Critical Care Medicine, Department of Medicine, "and the Department of Pharmacology," Northwestern University Feinberg School of Medicine, Chicago, Illinois

Accepted for publication October 6, 2020.

Address correspondence to You-Yang Zhao, Ph.D., Program for Lung and Vascular Biology, Stanley Manne Children's Research Institute, Ann \& Robert H. Lurie Children's Hospital of Chicago, $225 \mathrm{E}$ Chicago Ave., Box 205, Chicago, IL 60611. E-mail: youyang.zhao@northwestern. edu.

\begin{abstract}
Endothelial barrier integrity is required for maintaining vascular homeostasis and fluid balance between the circulation and surrounding tissues and for preventing the development of vascular disease. Despite comprehensive understanding of the molecular mechanisms and signaling pathways that mediate endothelial injury, the regulatory mechanisms responsible for endothelial regeneration and vascular repair are incompletely understood and constitute an emerging area of research. Endogenous and exogenous reparative mechanisms serve to reverse vascular damage and restore endothelial barrier function through regeneration of a functional endothelium and re-engagement of endothelial junctions. In this review, mechanisms that contribute to endothelial regeneration and vascular repair are described. Targeting these mechanisms has the potential to improve outcome in diseases that are characterized by vascular injury, such as atherosclerosis, restenosis, peripheral vascular disease, sepsis, and acute respiratory distress syndrome. Future studies to further improve current understanding of the mechanisms that control endothelial regeneration and vascular repair are also highlighted. (Am J Pathol 2021, 191: 52-65; https://doi.org/10.1016/j.ajpath.2020.10.001)
\end{abstract}

Endothelial cells (ECs) line the inner wall of blood vessels and form a semipermeable barrier, which regulates the flux of fluid, proteins, and blood cells across the vascular wall into parenchymal tissue and maintains an antithrombotic and anti-inflammatory state of the microvascular bed. ${ }^{1,2}$ Endothelial injury leads to complications associated with inflammation, including increased vascular permeability, transmigration of inflammatory cells, exit of erythrocytes, tissue edema, and microthrombosis. ${ }^{3}$ Endothelial barrier dysfunction is a key initiating event of various vascular diseases, including atherosclerosis and in-stent restenosis. ${ }^{1}$ Evidence from humans and animals has demonstrated the central role of endothelial leakage in determining the outcome of vascular diseases, including sepsis-induced lung injury. ${ }^{4-10}$ A better mechanistic understanding of endothelial regeneration and vascular repair is therefore of pivotal importance in the development of novel therapeutic strategies to promote endothelial integrity and vascular health.

After endothelial injury, the vascular repair process involves restoration of a functional endothelial monolayer (ie, endothelial regeneration) and reestablishment of the endothelial junctions to reform a semipermeable barrier (Figure 1). Endothelial regeneration may involve resident ECs themselves (ie, endogenous) and/or cells other than the resident EC population, such as the circulating stem/progenitor cells (ie, exogenous). Mechanisms that regulate endothelial barrier development and injurious junction

Supported in part by NIH grants R01HL148810 (Y.Y.Z.), $\begin{array}{llll}\text { R01HL123957 } & \text { (Y.Y.Z.), R01HL133951 } & \text { (Y.Y.Z.), R01HL140409 }\end{array}$ (Y.Y.Z.), and R35HL140014 (M.L.I.A); and American Heart Association Career Development Award 19CDA34500000 (C.E.E.).

Disclosures: None declared. 


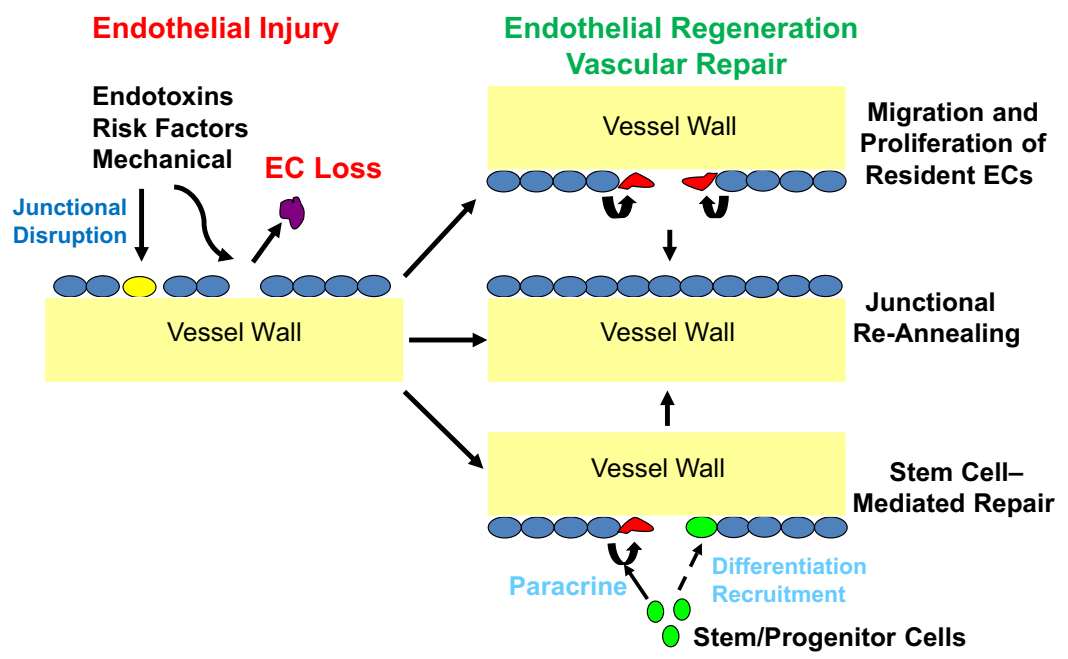

Figure 1 Processes of endothelial regeneration and vascular repair. Endothelial injury induced by inflammatory or mechanical stimuli as well as risk factors are characterized by endothelial cell (EC) death and/or disruption of endothelial cell-cell junctions, leading to increases in vascular permeability. The vascular repair process involves restoration of a functional endothelial monolayer (ie, endothelial regeneration) and reannealing of the endothelial junctions to restore a semipermeable barrier. Endothelial regeneration is primarily attributable to migration and proliferation of resident ECs. Evidence of bone marrow-derived stem/progenitor cell engraftment is limited (dashed line), but these cells can contribute to endothelial regeneration in a paracrine manner through the release of regenerative/reparative factors. leakage have been reviewed thoroughly by others. ${ }^{11}$ The current review describes the cellular and molecular mechanisms that control endothelial regeneration and recovery of endothelial barrier function after injury. Major unanswered research questions pertaining to endothelial regeneration and vascular repair are identified herein, and future studies that could improve understanding of regenerative and reparative endothelial signaling are discussed.

\section{Cellular Sources of Endothelial Regeneration}

\section{Circulating Cells Fail to Contribute Directly to Endothelial Regeneration}

The process of endothelial regeneration is thought to involve resident EC migration and proliferation and/or recruitment of circulating stem/endothelial progenitor cells (EPCs) that differentiate to ECs. Since the identification of circulating EPCs derived from the bone marrow (BM), ${ }^{12}$ investigating the role of EPCs in endothelial regeneration and vascular repair has become an active area of research. ${ }^{13-15}$ Studies have found that some circulating cells express the same surface markers and exhibit some properties in vitro similar to mature ECs. ${ }^{16,17}$ These studies indicate that circulating stem/progenitor cells may engraft into and function to regenerate the damaged endothelium. However, mounting evidence indicates that circulating EPCs (most likely monocytic) do not directly contribute to endothelial regeneration by forming part of the regenerating endothelium. Using BM cell transplantation and an ECspecific reporter, Ohle et $\mathrm{al}^{18}$ revealed a rare population of BM-derived cells $\left(\mathrm{CD} 45^{-} / \mathrm{CD} 31^{+} / \mathrm{CD} 144^{+}\right)$in recipient human lungs at 1 year after transplantation. However, these cells were not found in the anatomic compartment of the pulmonary vascular endothelium, indicating no involvement in endothelium maintenance. Furthermore, the study found no contribution of BM-derived cells to the endothelium of the adult lung, heart, liver, pancreas, or kidney after hyperoxic injury and recovery. In a study of lipopolysaccharide (LPS)-induced lung injury in mice, Kawasaki et $\mathrm{al}^{19}$ found that pulmonary EC number markedly decreases at 1 day after LPS administration but returns to baseline by day 7 . Subsequent studies with green fluorescent protein (GFP)-positive BM chimera mice revealed only a limited amount (approximately 2\%) of engraftment of BMderived ECs. However, $\mathrm{GFP}^{+}$ECs do not proliferate with minimal changes of total $\mathrm{GFP}^{+} \mathrm{ECs}$, which in fact decrease approximately $0.5 \%$ from $2 \%$ during the recovery from LPS-induced injury. Studies with direct $\mathrm{GFP}^{+} \mathrm{BM}$ cell transplantation without irradiation also found that $\mathrm{BM}$ $\mathrm{GFP}^{+}$cells hardly engrafted to pulmonary vascular endothelium or proliferated during the regenerative process. The total number of circulating EPCs (Flk1/KDR ${ }^{+} / \mathrm{CD} 133^{+}$or $\mathrm{Flk} 1 / \mathrm{KDR}^{+} / \mathrm{CD} 4^{+}$) is below the basal levels by day 7 after lung injury, indicating no engraftment to the injured lung endothelium. ${ }^{19}$ Hagensen et $\mathrm{al}^{20}$ also attempted to determine the role of circulating cells in endothelial regeneration. Wire-injured carotid artery segments from wild-type mice were transplanted into Tie2-GFP mice, demonstrating that the neoendothelium was negative for GFP and suggesting that circulating cells, including BM-derived EPCs, do not directly engraft to the injured endothelium to form a part of the regenerated endothelium. Using pairs of genetically marked parabiotic mice with a shared anastomosed circulatory system, Purhonen et $\mathrm{al}^{21}$ also demonstrated that BMderived circulating endothelial precursors do not contribute to endothelial regeneration.

Intriguingly, Singhal et $\mathrm{al}^{22}$ provided evidence of the contribution of BM-derived circulating cells to vascular repair in a murine hepatectomy model, but these cells did not directly contribute to endothelial regeneration by forming the regenerating endothelial layer. Using a partial hepatectomy model as well as chronic liver damage models where the liver vascular endothelium remains intact, Singhal et $\mathrm{al}^{22}$ observed no BM-derived cell incorporation into the new vessels. After irradiation-induced EC damage, 
BM-derived mononuclear cells were recruited and incorporated into the vasculature, but these cells failed to differentiate to ECs. Together, the recent studies using genetic lineage tracing and experimental parabiosis as well as advanced imaging techniques provide convincing evidence that BM-derived cells and circulating EPCs are not the major source of ECs that make up the regenerating endothelium. Nevertheless, endothelial regeneration and vascular repair seems to benefit from factors released from circulating progenitor cells, and such factors could play a role in these regenerative and reparative process (Figure 1). These exogeneous paracrine mechanisms are described later in the article.

\section{Regeneration of the Endothelium by Tissue Resident ECs}

To gain insights into the role of tissue resident ECs in the mechanism of endothelial regeneration, approaches such as genetic lineage tracing have been used. Using Tie2Cre-GFP mice, Itoh et $\mathrm{al}^{23}$ found that recovery of the EC-denuded middle cerebral artery by photochemical injury required a combination of resident EC elongation and migration from both ends of the injury site and resident EC proliferation, without observing involvement of exogenous progenitor cells. Their findings were further supported by a mouse model of aortic EC injury induced by compression clamping and a genetic lineage tracing (Cdh5Cre-ERT2) approach. ${ }^{24}$ In those studies, McDonald et $\mathrm{al}^{24}$ found that regenerating ECs arose from sites immediately adjacent to the site of injury with no contribution from circulating cells. These authors also found that the regenerative ECs [ $80 \%$ of which are $\mathrm{Cdh}^{+}$/activating transcription factor $3\left(\mathrm{Atf}^{+}\right)$] altered their transcriptional profile and acquired significant proliferative potential. The process relies on activation of key stress response genes, particularly ATF3. They also found that the regenerative response is significantly impaired in older mice in which levels of Atf 3 decrease. Regarding the contribution of resident ECs to endothelial regeneration in the murine liver, Singhal et $\mathrm{al}^{22}$ found that regeneration was mediated solely by resident ECs (Cdh5Cre-ERT2-mediated labeling) when resident ECs were intact after partial hepatectomy or carbon tetrachloride-induced chronic damage or adenoviral infection. When resident ECs were damaged via irradiation, BM-derived cells were recruited and incorporated into the injured vasculature, but these cells failed to differentiate to ECs. A recent study ${ }^{25}$ using genetic lineage tracing with Cre recombinase expression driven by the $5^{\prime}$ endothelial enhancer of the stem cell leukemia locus (EndoSCL-CreERT2) demonstrated that the resident EC population decreases after inflammatory lung injury in mice, then recovers to a level similar to that found at baseline. This study also identified an increase in lung EC proliferation during recovery from sepsis challenge. Thus, lung endothelial regeneration is mediated by tissue-resident EC proliferation after inflammatory vascular injury. ${ }^{9}$ These studies together provide strong evidence that the tissueresident EC population is the major source of regenerating ECs during endothelial regeneration (Figure 1), but the specific main driving mechanisms might be distinct in large versus small vessels and distinct in different organs, which will be discussed below.

\section{Specialized Tissue-Resident ECs Responsible for Endothelial Regeneration}

Heterogeneity is a characteristic feature of ECs. ${ }^{26,27}$ Recent studies have tried to identify and define potential specialized tissue-resident ECs responsible for endothelial regeneration. In a study mentioned above, Kawasaki et $\mathrm{al}^{19}$ found that a subpopulation of lung resident ECs $\left(\mathrm{CD} 34^{+} / \mathrm{Flk}-1 / \mathrm{KDR}^{+} / \mathrm{c}-\right.$ $\mathrm{kit}^{+}$) with progenitor cell characteristics is largely responsible for lung endothelial regeneration after acute lung injury in mice. Experiments using BM chimeric mice revealed that most of the regenerating pulmonary vascular ECs are tissue-resident cells, whereas BM-derived cells barely engraft as pulmonary vascular ECs. The regenerating pulmonary vascular ECs are characterized by high colonyforming and vasculogenic capacities with high expression of CD34, Flk-1/KDR, and c-kit and low expression of Prom1/CD133 on the cell surface when compared with nonproliferating pulmonary vascular ECs. In a study by Wakabayashi et al, ${ }^{28}$ a subpopulation of CD157-expressing regenerative tissue-resident endothelial stem cells was identified in the arteries and veins but not capillaries of numerous mouse organs, including liver, lung, heart, skeletal muscle, skin, retina, and brain. These cells were able to regenerate entire vasculature structures after injury and maintain large vessels in the healthy liver for $>12$ months. As discussed above, McDonald et $\mathrm{al}^{24}$ identified two subpopulations of resident ECs that contribute to endothelial regeneration in the injured aortic endothelium, and the $\mathrm{CdhS}^{+} / \mathrm{Atf3}^{+}$subpopulation is the dominant subpopulation (approximately 80\%) responsible for endothelial regeneration.

These studies have defined the predominant role of resident endothelial cell proliferation in the mechanisms of endothelial regeneration. Genetic lineage tracing studies have found that $>95 \%$ of the regenerative ECs are derived from resident ECs. Both BM-derived and circulating progenitor cells rarely engraft and differentiate into ECs. The relative contribution of the cells other than resident ECs should be defined by genetic lineage tracing. In addition, there is an interesting subpopulation called mesoangioblasts. These vessel-associated multipotent cells often express endothelial and/or pericyte markers, such as platelet-derived growth factor receptor $\beta, \mathrm{CD} 271, \mathrm{CD} 73$, EMCN, and delta-like 1 (DLK1), ${ }^{29,30}$ and are able to form vessel-like structures. ${ }^{31}$ Although the contribution of mesoangioblasts to cardiac regeneration has been well studied, ${ }^{30,32}$ the role of mesoangioblasts in endothelial regeneration and vascular repair remains unclear. 


\section{Transcription Factors That Mediate Endothelial Regeneration}

FoxM1

FoxM1 is a member of the mammalian forkhead box family of transcription factors that share homology in the winged helix or forkhead DNA binding domain. ${ }^{33}$ FoxM1 expression is markedly induced in lung ECs in the recovery phase but not in the injury phase after endotoxemia. ${ }^{9}$ The role of this transcription factor in the recovery of the pulmonary endothelium after injury has been investigated using mice that lack endothelial FoxM1. ${ }^{9}$ EC-specific Foxml knockout mice exhibited impaired EC proliferation and persistent increases in lung vascular permeability despite a similar degree of peak injury compared with that seen in wild-type mice. Overexpression of FoxM1 enhanced endothelial proliferation and thus facilitated the recovery of endothelial barrier integrity and promoted survival. ${ }^{34}$

\section{HIF- $1 \alpha$}

Hypoxia-inducible factors (HIFs) are critical mediators of the adaptive response to hypoxia and ischemia. These heterodimeric proteins consist of a constitutively expressed $\beta$-subunit and an oxygen-labile $\alpha$-subunit that has three isoforms (HIF- $1 \alpha$, HIF- $2 \alpha$, and HIF- $3 \alpha$ ). ${ }^{35,36}$ Huang et $\mathrm{al}^{37}$ found that HIF- $1 \alpha$ but not HIF- $2 \alpha$ is rapidly induced and stabilized in murine pulmonary vascular ECs after sepsis challenge. Mice with EC-specific disruption of Hifla exhibited impaired lung endothelial regeneration and vascular repair in contrast to wild-type mice, despite similar levels of peak lung injury. Forced expression of FoxM1 in lung ECs of conditional Hifla knockout mice normalized EC proliferation and vascular repair, indicating that endothelial HIF- $1 \alpha$ is required for endothelial regeneration and vascular repair via FoxM1mediated EC proliferation after sepsis-induced lung injury.

\section{Sox17}

Sox17 is a member of the Sry-related high-mobility group domain family $\mathrm{F}$ (SoxF) transcription factors and a key developmental regulator of endothelial and hematopoietic lineages. ${ }^{38}$ After sepsis challenge in mice, Sox 17 is markedly induced in pulmonary vascular ECs in as little as 6 hours. ${ }^{25}$ EC-specific deletion of Sox 17 resulted in decreased EC proliferation and a persistent increase in pulmonary vascular permeability in response to endotoxemia. Conversely, overexpression of Sox17 in lung ECs enhanced lung EC proliferation and regeneration and promoted survival. Promoter analysis identified Sox 17 as a transcriptional target of HIF- $1 \alpha$.

\section{Atf3}

In the regenerating endothelium of large murine blood vessels, the stress-inducible transcription factor, ATF3, is a key transcription factor. ${ }^{24}$ ATF3 is a member of the ATF/ CREB family of transcription factors involved in many human diseases, including cancer and atherosclerosis. ${ }^{39,40}$ ATF3 is highly expressed in proliferating ECs after mechanical pressure injury of the murine aortic endothelium imposed by a clamp. ${ }^{24}$ Global Atf3 knockout mice have a significant reduction in EC proliferative capacity and defective endothelial regeneration, resulting in impaired wound closure after mechanical pressure-induced injury of the aortic endothelium.

\section{Signaling Pathways Responsible for Endothelial Regeneration and Vascular Repair}

\section{P110 PI3K Signaling}

Huang et $\mathrm{al}^{10}$ found that endothelial FoxM1 induction after sepsis-induced lung injury in mice was mediated by the Gcoupled protein receptor (GPCR)-dependent p110 $\gamma$ isoform of phosphoinositide 3-kinase (PI3K). Global Pik3cg knockout mice had defective pulmonary endothelial proliferation and persistent inflammatory injury after sepsis challenge despite similar levels of peak lung injury. Restoration of EC-specific FoxM1 expression in Pik3cg global knockout mice promoted EC regeneration and normalized the repair process. Furthermore, Huang et $\mathrm{al}^{10}$ observed diminished expression of p110 $\gamma$ in pulmonary vascular ECs taken from patients with acute respiratory distress syndrome (ARDS). The authors also found that this regenerative pathway is not limited to the pulmonary vasculature but is also operative in the systemic vasculature. Defective vascular repair was also observed in the cremaster muscle venules in Pik3cg-null mice, which was normalized in Pik3cg-null mice with transgenic expression of FoxM1. Mechanistically, p110 $\gamma$ induced FoxO phosphorylation and translocation out of the nucleus, which resulted in FoxM1 induction. The study by Huang et $\mathrm{al}^{10}$ further found evidence that stromal cell-derived factor 1 is a possible upstream GPCR-mediated ligand responsible for $\mathrm{p} 110 \gamma$ activation after sepsis challenge. These studies found the crucial role of the endogenous EC-specific p110 $\gamma \mathrm{PI} 3 \mathrm{~K}-$ FoxM1 signaling axis in endothelial regeneration and vascular repair afer inflammatory injury.

\section{miRNA-126 Signaling}

The autocrine and paracrine roles of miRNAs in EC regeneration by resident ECs have also been studied. Schober et $\mathrm{al}^{41}$ found that $\mathrm{EC}$ recovery after denudation was impaired by lack of miRNA-126-5p in global knockout mice, which reduced EC proliferation through activation of the Notch1 inhibitor, Dlk1 homolog. Down-regulation of $m i R-126-5 p$ by disturbed flow abrogated EC proliferation at athero-prone sites in response to hyperlipidemic stress through up-regulation of Dlk1 expression, whedreas administration of $m i R-126-5 p$ rescued EC proliferation at 
athero-prone sites and limited atherosclerosis. On the other hand, Jansen et $\mathrm{al}^{42}$ found that coronary artery ECs can promote EC repair in mice through microparticle-mediated transfer of miRNA-126, which increases EC migration and proliferation. The miR-126 from damaged ECs was acquired by recipient human coronary artery ECs via endothelial microparticles and functionally regulated the expression of the target protein sprout-related EVH1 domain-containing protein 1 (SPRED1). Knockdown of $m i R-126$ in EC microparticles abrogated the EC microparticle-mediated effects on human coronary artery EC migration and proliferation. Intriguingly, miR-126 expression was reduced in circulating microparticles from patients with diabetes. ${ }^{42}$ In a separate study, miR-126 enhanced the angiogenic actions of vascular endothelial growth factor (VEGF) and fibroblast growth factor and promoted neovessel formation by suppressing the expression of SPRED1 in mice, which reduces EC migration and proliferation by inhibiting Ras/mitogen-activated protein kinase signaling in vitro. ${ }^{43}$

\section{Notch1 Signaling}

As described above, miRNA126-regulated Dlk1 inhibits endothelial proliferation and regeneration. ${ }^{41}$ Recent studies have also revealed that discrete types of non-ECs can drive EC regeneration. In a study using smooth muscle cell (SMC)-EC co-cultures, researchers have found that SMC$\mathrm{EC}$ contact is required for the activation of Notch1 by bone morphogenic protein receptor 2 (BMPR2) in both ECs and SMCs and for EC regeneration after wire-induced carotid artery injury in mice. ${ }^{44}$ BMPR2 is necessary to produce collagen IV, which in turn activates integrin-linked kinase directing phospho-c-Jun N-terminal kinase to the EC membrane, which stabilizes presenilin1 and releases notch1 intracellular domain(NICD1). NICD1 increased mitochondrial mass and induced expression of 6-phosphofructo-2kinase/fructose-2,6-biphosphatase 3 (a key metabolism regulator), which itself is necessary for citrate-dependent acetylation of H3K27. Thus, BMPR2-mediated activation of Notch1 coordinates EC metabolism with histone acetylation to induce expression of the Notch1 target Myc, and in turn, Myc-regulated genes, such as apelin and heme oxygenase 1, ultimately leading to EC proliferation and regeneration.

\section{Apelin Signaling}

A recent study by Masoud et $\mathrm{al}^{45}$ found that apelin directs EC differentiation and vascular repair after immune-mediated injury. They also found that human and mouse heart allografts with alloimmune-mediated vasculopathy had increased expression of apelin in arteries and myocardial microvessels. Loss of apelin expression in the donor heart promoted graft immune cell infiltration, impaired vascular repair, and increased occlusive vasculopathy in mice. In contrast, an apelin receptor agonist induced endothelial nitric oxide synthase activation, promoted endothelial monolayer wound repair, and reduced immune cell adhesion. Treatment with the apelin receptor agonist also reduced progression of arterial occlusion in mice. A separate study found that hypoxiainduced expression of apelin modulates EC proliferation and regeneration in zebrafish. ${ }^{46}$ These authors found that apelin is induced by hypoxia in human pulmonary vascular lung ECs and SMCs. Furthermore, miRNA against apelin or APJ receptor knockdown inhibited hypoxia-induced EC proliferation in vitro and vessel regeneration in zebrafish. Together, these data identify apelin as a key regulator of vascular endothelial regeneration.

\section{VEGF Signaling}

In rat models of nephritis, Ostendorf et $\mathrm{al}^{47}$ found that VEGF inhibition reduced glomerular endothelial regeneration and increased EC death without altering proteinuria. In a model of balloon angioplasty-induced endothelial denudation of the rabbit carotid artery, VEGF treatment increased endothelial regeneration. ${ }^{48}$ In a coronary stent implantation model in minipigs, overexpression of VEGF receptor reduced neointimal proliferation, suggesting that VEGF signaling promotes endothelial regeneration after coronary injury. ${ }^{49}$ Similarly, in a mouse model of arterial endothelial denudation, adenoviral VEGF treatment increased luminal EC proliferation and accelerated endothelial repair, whereas VEGF inhibition had the opposite effects. ${ }^{50}$ These studies identify VEGF as an important factor for EC proliferation and regeneration and vascular repair.

\section{Other Signaling Molecules}

Endothelial-specific overexpression of insulin-like growth factor (IGF)-1 receptor (IGF1R) in transgenic mice promotes endothelial regeneration in a wire injury model of the femoral artery but reduces nitric oxide bioavailability, whereas $I g f l r$ heterozygous knockout mice have reduced endothelial regeneration. ${ }^{51} \mathrm{EC}$ isolated from lungs of the transgenic mice exhibit enhanced migration in vitro compared with wild-type ECs. Dimethylaminohydrolases degrade asymmetric dimethylarginine, which is an endogenous nitric oxide synthase inhibitor. Konishi et $\mathrm{al}^{52}$ found that overexpression of dimethylaminohydrolase 1 promotes endothelial regeneration in the murine femoral artery after wire injury.

The studies summarized in the two sections above have identified the molecular mechanisms (transcriptional factors and signaling pathways) of endothelial regeneration and vascular repair in the systemic vasculature (Figure 2) and pulmonary vasculature (Figure 3 ). It appears that different vascular beds use different molecular mechanisms for endothelial regeneration. These differences may be ascribed to different injury models as well as different sizes of vessels (endothelial denudation in large arteries in the systemic vasculature versus inflammatory endothelial injury in 


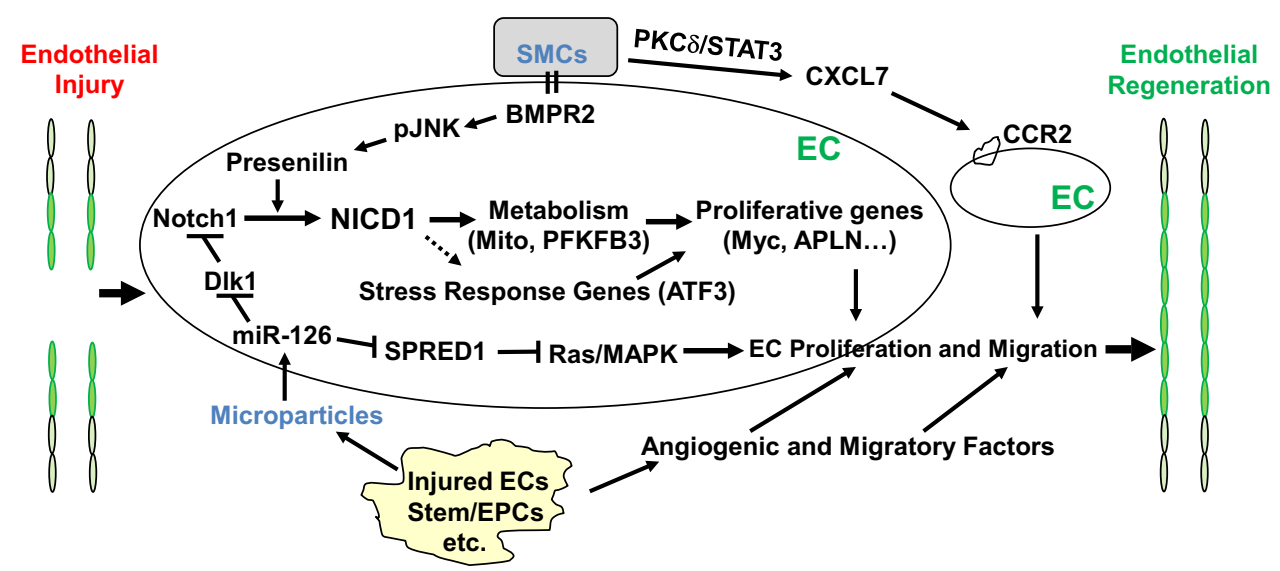

Figure 2 Molecular and signaling mechanisms of endothelial regeneration and vascular repair in systemic arterial vessels after endothelial injury induced by mechanical or electrical denudation. Several studies that used carotid artery injury models have found an important role of endothelial Notch1 activation in the mechanism of endothelial proliferation. Microparticle-released miR-126 also plays an important role in endothelial proliferation and migration through inhibition of the Notch inhibitor delta-like 1 (Dlk1) and sprout-related EVH1 domain-containing protein 1 (SPRED1), Ras, and mitogen-activated protein kinase (MAPK) signaling. Smooth muscle cell (SMC) interaction with endothelial cells (ECs) promotes Notch1 activation through bone morphogenic protein receptor 2 (BMPR2) signaling, leading to EC proliferation. SMCs also release various factors (eg, CXCL7) to activate CCR2 signaling in the neighboring ECs and promote their migration for reendothelialization. Injured ECs and other cells, such as stem/progenitor cells, release microparticles and angiogenic and migratory factors and therefore promote endothelial regeneration. In an aorta mechanical pressure injury model, the stress response gene ATF3 plays an important role in mediating endothelial regeneration and vascular repair. NICD1, notch1 intracellular domain; PFKFB3, phosphofructo-2-kinase/fructose-2,6-biphosphatase 3; pJNK, phospho-c-Jun N-terminal kinase; PKC- $\delta$, protein kinase $C \delta$.

microvessels in the pulmonary vasculature). Zhao et $\mathrm{al}^{9}$ identified the important role of endothelial FoxM1 in mediating endothelial regeneration in mouse lungs after inflammatory injury induced by endotoxiemia, whereas McDonald et $\mathrm{al}^{24}$ found that loss of endothelial FoxM1 has only delayed endothelial wound closure without affecting endothelial proliferation in injured aortic endothelium by mechanical pressure. However, in another study, p110 $\gamma \mathrm{PI} 3 \mathrm{~K}$ signaling is required for FoxM1-depedent endothelial regeneration and vascular repair in the pulmonary vasculature and cremaster muscle venules (systemic vasculature) in the same inflammatory injury model. ${ }^{10}$ Future studies are warranted to determine whether different vascular beds and different sizes of vessels share some of the molecular mechanisms for regeneration of the endothelium using the same injury model.

\section{Re-Annealing of Endothelial Junctions to Restore Endothelial Barrier Integrity}

Healing of the injured endothelium involves reestablishment of endothelial junctions to restore endothelial barrier integrity. Interendothelial junctions include adherens junctions (AJs), tight junctions, and gap junctions. ${ }^{11}$ AJs and tight junctions form molecular connections between adjacent ECs, promoting a strong seal along the EC perimeters. In contrast, gap junctions do not contribute to homotypic attachment but instead form intracellular channels, allowing for chemical and electrical communication between neighboring ECs. Interendothelial junctions that connect the continuous monolayer of ECs impose restrictions in the movement of fluid, proteins, and blood cells across the endothelium and constitute a semipermeable barrier. Weakening or loss of interendothelial junctions results in transport of proteinaceous fluid into the perivascular space, which in turn leads to tissue edema, a common characteristic of a broad range of pathologic findings. Endothelial barrier permeability is largely regulated by AJs, which respond to mechanical and chemical stimuli under physiologic and pathologic conditions. ${ }^{11,53}$ The AJ complex is composed of vascular endothelial cadherin (VE-cadherin), $\beta$-catenin or plakoglobin, $\alpha$-catenin, and p120-catenin. Homotypic interaction between the extracellular domains of VEcadherin adheres two neighboring ECs together to form the junctions, whereas its cytoplasmic domains bind to p120-catenin and $\beta$-catenin or plakoglobin. In turn, $\beta$-catenin binds with the actin-associated protein $\alpha$-catenin. Transcriptional and posttranslational modifications of these junctional proteins, as well as cellular and molecular signaling pathways, mediate the plasticity of the endothelial junctions and, in doing so, regulate endothelial permeability. ${ }^{11,53}$ ECs also express N-cadherin, which regulates VE-cadherin expression and recruitment to the AJs and thus endothelial barrier integrity. ${ }^{54}$ Although mechanisms that regulate endothelial barrier development and injurious junction leakage have been reviewed thoroughly by others, ${ }^{11,53}$ this section summarizes the mechanisms involved in the reannealing of endothelial junctions and restoration of endothelial barrier integrity after injury.

\section{$\beta$-Catenin Regulated by FoxM1 and SHP2}

Using EC-restricted disruption of Foxm1 in mice and primary human lung microvascular ECs, Mirza et $\mathrm{al}^{7}$ 
found that FoxM1 is required for endothelial AJ recovery via its transcriptional control of $\beta$-catenin. In mouse lungs and human lung microvascular ECs, conditional FoxM1 deletion resulted in persistent increases of vascular leakage and defective endothelial barrier recovery after thrombin-induced disruption of the endothelial barrier. However, loss of endothelial FoxMI did not affect the extent of vascular leakiness during the injury phase. Restoration of $\beta$-catenin expression in Foxml-null ECs inhibited the defective barrier recovery in Foxm1 ECspecific knockout mice and cultured human lung ECs. In a separate study, Timmerman et $\mathrm{al}^{55}$ found that $\beta$ catenin is a substrate of the Src homology 2 (SHP2) domain that contains tyrosine phosphatase. SHP2 regulates the recovery of disrupted EC junctions by dephosphorylating $\beta$-catenin associated with VE-cadherin and thus stimulating VE-cadherin mobilization at the plasma membrane. These studies emphasize the important role of $\beta$-catenin as a junctional protein in mediating reannealing of the endothelial AJs and driving the recovery of endothelial barrier integrity.

\section{$\mathrm{G} \beta \gamma$, Fyn, and FAK Signaling}

The heterotrimeric G-protein complex is composed of the $\mathrm{G} \alpha$ and $\mathrm{G} \beta \gamma$ subunits. On stimulation with the inflammatory mediator thrombin, the $\mathrm{G} \alpha$ subunit is dissociated from the $G \beta \gamma$ subunit, which signals the increase in endothelial permeability. The released $G \beta \gamma$ subunit is reported to play an important role in reannealing of the endothelial AJs. ${ }^{56}$ Defective $\mathrm{G} \beta \gamma$ function prevents reestablishment of the AJs and thus persistent vascular leaking, although it does not affect the permeability increase after thrombin treatment. Thrombin induces G $\beta$ dissociation from RACK1 and subsequent interaction with Fyn. Fyn-dependent phosphorylation of focal adhesion kinase (FAK) induces association of FAK with the endothelial AJs and mediates endothelial barrier recovery. Global Fyn knockout mice exhibit

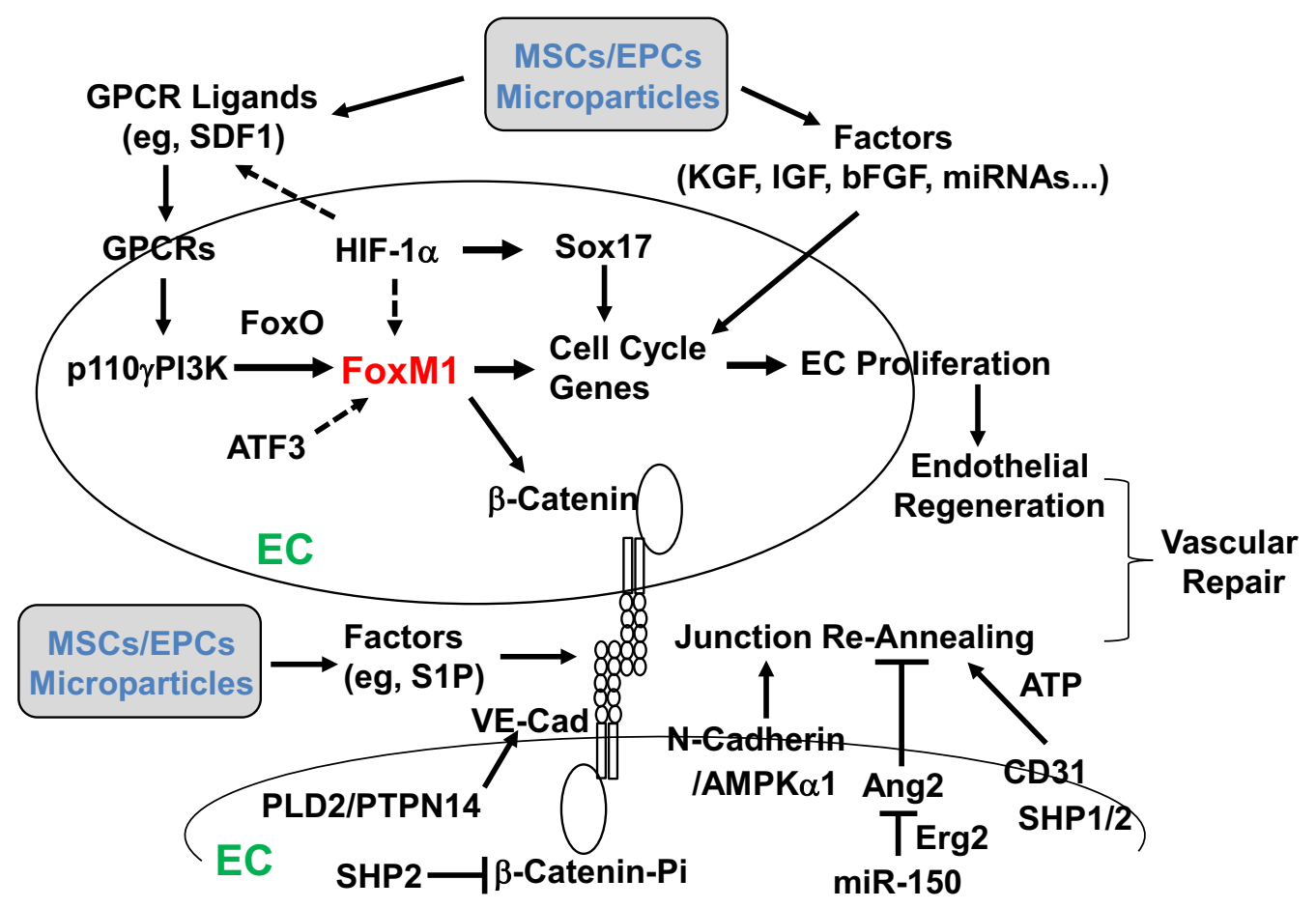

Figure 3 Molecular and signaling mechanisms of endothelial regeneration and vascular repair in pulmonary vasculature after inflammatory injury. Studies have found a critical role of the transcriptional factor FoxM1 in mediating endothelial cell (EC) proliferation and endothelial regeneration after inflammatory vascular injury. FoxM1 is induced in lung vascular ECS only in the recovery phase after injury in a p110 $\gamma$ isoform of phosphoinositide 3-kinase (p110 $\gamma \mathrm{PI} 3 \mathrm{~K}$ ) dependent manner. Recent studies have further found that hypoxia-inducible factor (HIF)-1 $\alpha$ mediates expression of FoxM1 and Sox17 to promote endothelial regeneration. Transplanted exogenous stem/progenitor cells act in a paracrine mechanism by releasing various growth factors, including stromal cell-derived factor 1 (SDF1) and insulin-like growth factor (IGF) as well as miRNA. Endothelial FoxM1 is one of the endogenous mediators of the paracrine effects. Vascular repair also involves reannealing of endothelial cell-cell junctions to reform a semipermeable barrier. One study found that $\beta$-catenin is the transcriptional target of FoxM1. Endothelial FoxM1 deficiency impairs endothelial barrier recovery though defective $\beta$-catenin expression. 0ther studies also found a role of Src homology 2 (SHP2) dephosphorylation of vascular endothelial cadherin (VE-cadherin)-associated $\beta$-catenin and phospholipase D2 (PLD2)/protein tyrosine phosphatase nonreceptor type 14 (PTPN14) dephosphorylation of VE-cadherin, AMP-activated protein kinase (AMPK)- $\alpha_{1} / \mathrm{N}-\mathrm{cadherin}$, and miR-150/Erg2/ angiopoietin-2 (Ang2) signaling as well as stem/progenitor cell-released reparative factors, such as sphingosine-1 phosphate (S1P), in re-annealing the endothelial cell-cell junctions and restoring the endothelial barrier after injury. bFGF, basic fibroblast growth factor; EPCs, endothelial progenitor cells; GPCR, G-coupled protein receptor; KGF, keratinocyte growth factor; MSCs, mesenchymal stem cells. 
impaired vascular repair, and endothelial expression of the FAK phosphorylation mutant results in FAK activation and normalization of vascular repair in $\mathrm{Fyn}^{-1-}$ mice. These data indicate that $G \beta \gamma$-mediated Fyn activation integrates FAK with the endothelial AJs and mediates vascular repair.

\section{AMPK and N-Cadherin}

AMP-activated protein kinase (AMPK) is a molecular sensor triggered by stimuli that disrupt the vascular endothelium and subsequently mediates the recovery of the endothelial barrier. In pulmonary microvascular ECs, the $\alpha_{1}$-subunit of AMPK is required for the reformation of cellcell networks and for the repair of EC monolayers after in vitro wounding. ${ }^{57}$ AMPK- $\alpha_{1}$ co-localizes with the AJ protein, $\mathrm{N}$-cadherin, and in isolated lungs, AMPK activation contributes to EC barrier recovery. In a subsequent study on AMPK- $\alpha_{1}$, Jian et $\mathrm{a}^{58}$ found that AMPK stimulation by metformin treatment decreased the LPS-induced increase in lung vascular permeability in rats and resolved pulmonary edema in vivo. In ex vivo perfused rat lungs and isolated pulmonary microvascular ECs, AMPK- $\alpha_{1}$ was responsible for endothelial barrier recovery after EC injury, a process coordinated by N-cadherin. Disruption of N-cadherin's intracellular domain causes translocation of AMPK away from the membrane and attenuates AMPK-mediated restoration of barrier function in LPS-treated endothelium. Inhibition of N-cadherin impaired AMPK-mediated vascular repair in murine lungs after LPS challenge. ${ }^{59}$

\section{CD31, SHP, and Metabolic Reprogramming}

CD31 is expressed at high density at the lateral borders of ECs. CD31 deficiency has been associated with excessive vascular leakage after endothelial injury induced by histamine, thrombin, and LPS-induced endotoxemia. Using the major histocompatibility complex activation-induced endothelial barrier disruption model, Cheung et $\mathrm{al}^{60}$ found that endothelial barrier recovery requires a CD31-induced glycolytic response that sustains endothelial AJ reassembly. The metabolic reprogramming requires SHP1/2 activation, leading to Akt-mediated nuclear exclusion of FoxO1 and concomitant $\beta$-catenin translocation to the nucleus, thus inducing cMyc transcription. Pharmacologic Akt or AMPK activation normalizes vascular repair and inhibits pathologic vascular leakage in $C D 31^{-1-}$ mice via augmented glycolytic flux in ECs. These studies indicate the requirement of glycolysis-produced ATP in reestablishing endothelial AJs and repairing the leaking vessels.

\section{Phospholipase D2/PTPN14}

VE-cadherin recycling to AJs and dephosphorylation of tyrosine phosphorylated VE-cadherin promotes junctional reassembly and restoration of endothelial barrier function. Fu et $\mathrm{al}^{61}$ found that inhibition of phospholipase D2 (PLD2) activity resulted in prolonged phosphorylation of Tyr-658 in VE-cadherin in human lung microvascular ECs during the recovery phase after thrombin challenge and thus impaired endothelial barrier recovery via inhibition of protein tyrosine phosphatase nonreceptor type 14 (PTPN14). After thrombin challenge, PLD2, PTPN14, and VE-cadherin form a complex to facilitate PTPN14 dephosphorylation of VEcadherin. PTPN14 depletion impaired reannealing of endothelial AJs and barrier recovery in human lung microvascular ECs. In $P l d 2^{-1-}$ mice, lung vascular permeability failed to recover from PAR-1-activating peptide-induced injury. Together, these studies indicate that PLD2 promotes PTPN14-mediated dephosphorylation of VEcadherin, which leads to recycling of VE-cadherin at the AJs for recovery of endothelial barrier function.

\section{Ang2 and miRNA-150}

Rajput et $\mathrm{al}^{62}$ found that miRNA-150 expression was elevated only during the recovery phase after murine lung injury. Deletion of miRNA-150 in mice resulted in a sustained increase in angiopoietin-2 (Ang2) levels, blocked repair of AJs after injury, increased vascular permeability, and promoted rapid postsepsis mortality. In contrast, restoration of miRNA-150 expression in ECs of global miRNA150 knockout mice inhibited Ang2 production via targeting of the transcription factor early growth response 2(Egr2), which restored endothelial barrier function. Deletion of Egr2 or Ang2 in miR-150 ${ }^{-1-}$ ECs restored junctional reannealing and reinstated endothelial barrier function. ${ }^{62}$ Overall, these studies found that restoring endothelial junctional integrity provides a therapeutic avenue for diseases characterized by vascular leakage.

\section{Regulation of Endothelial Regeneration by Paracrine Factors from 0ther Cells}

Although evidence reviewed earlier in the article suggests that nonresident/circulating cells are not a major source of regenerating endothelium, the numbers of circulating EPCs are correlated with disease risk, severity, or outcome in conditions that are characterized by vascular injury, such as cerebrovascular disease and sepsis. ${ }^{63,64}$ Exogenous administration of mesenchymal stem cells (MSCs) or BM-derived progenitor cells can inhibit inflammatory lung injury and promote survival after sepsis challenge. ${ }^{65-72}$ Importantly, MSC therapy shows promise for the treatment of patients with ARDS. ${ }^{73,74}$ It is now thought that BM-derived cells as well as exogenously administered adult stem cells (eg, MSCs) could promote endothelial regeneration and vascular repair through paracrine mechanisms, particularly given the studies described above that found that these cell types rarely engraft into the vasculature.

One such study clearly found the paracrine function of these stem/progenitor cells in promoting endothelial 
Table 1 Molecules That Regulate Endothelial Regeneration and Barrier Recovery

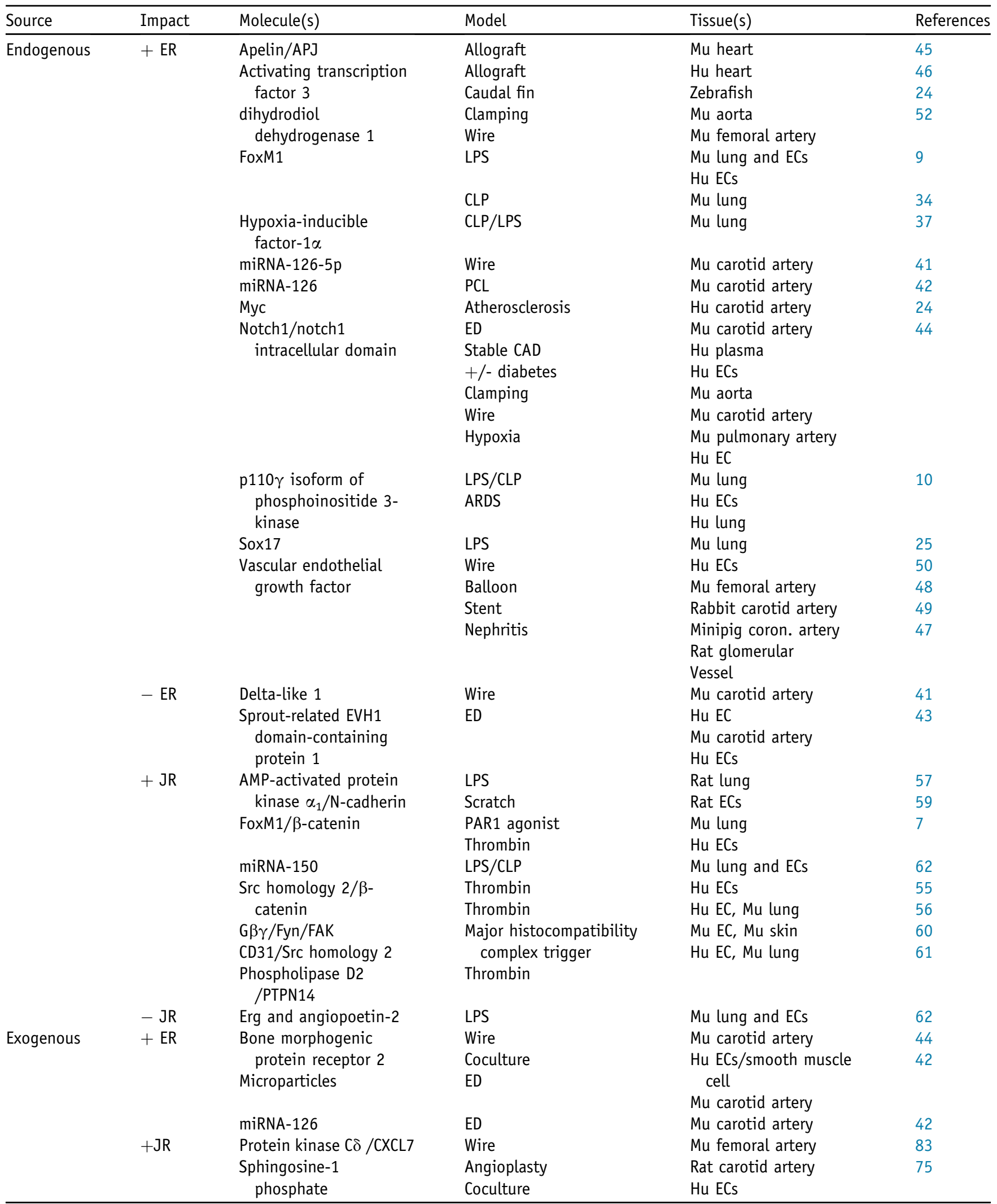

Molecules that have either a beneficial ( + ) or inhibitory (-) effect on ER or JR have been identified by experimental studies of isolated ECs and multiple organs and species.

CLP, cecal ligation and puncture; EC, endothelial cell; ED, electric denudation; ER, endothelial regeneration; Hu, human; JR, junction reannealing; LPS, lipopolysaccharide; $\mathrm{Mu}$, mouse; $\mathrm{PCL}$, partial carotid ligation. 
regeneration and vascular repair. ${ }^{75}$ The study found that induction of endogenous FoxM1 expression in ECs is required for the reparative effects of transplanted BM progenitor cells in mice. Transplantation of cultured BM progenitor cells induced resolution of inflammatory lung injury and survival in wild-type mice, but these effects were abrogated in FoxMl-EC knockout mice after inflammatory injury. This study found that progenitor cell treatment failed to induce pulmonary EC proliferation and thereby endothelial regeneration and vascular repair in FoxM1-EC knockouts. Intriguingly, Foxml deletion in ECs did not affect the early protective effects of exogenous progenitor cells, consistent with the selective role of endothelial FoxM1 in mediating endothelial regeneration and vascular repair. Furthermore, this study found that treatment of wildtype but not FoxM1-deficient EC monolayers with BMderived progenitor cells resulted in enhanced endothelial barrier function, whereas restoration of $\beta$-catenin in Foxm 1null ECs reenabled progenitor cell-induced enhancement of endothelial barrier function. Thus, transplantation of exogenous adult progenitor cells promoted endothelial regeneration and reannealing of endothelial AJs for restoration of endothelial barrier integrity through paracrine activation of endothelial expression of FoxM1.

One of the potential key paracrine factors from the adult stem/progenitor cells is sphingosine-1 phosphate, which promotes FoxM1-dependent endothelial junction recovery. ${ }^{75}$ Furthermore, adult stem/progenitor cells can release several proangiogenic factors, such as keratinocyte growth factor, IGF-1, basic fibroblast growth factor, and VEGF. ${ }^{76-78}$ Future studies should investigate the individual role of these angiogenic factors in activating endothelial regeneration and vascular repair.

Recent studies also found that adult stem/progenitor cells (as well as ECs themselves) can release microparticles or microvesicles that induce endothelial regeneration by promoting proliferation of tissue-resident ECs. ${ }^{79-82}$ Microparticles are small membrane fragments released from cells and may contain DNA, RNA, or miRNA. These microparticles can, in turn, be uptaken by resident ECs to activate the endothelial regeneration program. ${ }^{80}$ Jansen et $\mathrm{al}^{42}$ found that injected endothelial microparticles promote endothelial regeneration after electric endothelial denudation of carotid artery in mouse via transfer of miRNA-126, which increases EC migration and proliferation. In their study, miR-126 functionally regulated the target protein SPRED1. Furthermore, knockdown of miR-126 in endothelial microparticles abrogated their effects on human coronary artery EC migration and proliferation in vitro and reendothelialization in vivo.

Other studies have revealed that SMCs can also drive EC regeneration. As described above, Miyagawa et $\mathrm{al}^{44}$ recently found that SMC-EC contacts promote EC regeneration after wire-induced carotid artery injury in mice. BMPR2 was required by both cell types to produce collagen IV, which activates integrin-linked kinase and directs phospho-c-Jun
$\mathrm{N}$-terminal kinase to the EC membrane, where it stabilizes presenilin1 to activate Notch1to promote EC proliferation.

Ren et al ${ }^{83}$ also recently investigated whether SMCs can modulate EC regeneration in a paracrine manner. Using a mouse model of wire-induced arterial injury and a rat model of carotid angioplasty, the authors found that inactivation of protein kinase $\mathrm{C}$ (PKC)- $\delta$ in SMCs impairs EC regeneration, whereas gene transfer of PKC- $\delta$ to the SMCs of these animals promoted $\mathrm{EC}$ regeneration. Conditioned medium taken from SMCs infected with PKC- $\delta$ adenoviruses could be used to induce EC migration but not proliferation. CXCL7 was expressed in SMCs in a PKC- $\delta / S T A T 3-d e p e n d e n t$ manner. Blockade of CXCL7 or its receptor (CXCR2) attenuated EC migration and inhibited endothelial wound closure. Thus, SMCs stimulate EC regeneration via PKC$\delta$-dependent expression of CXCL7, which likely leads to recruitment of ECs from uninjured endothelium for vascular repair. Taken together, it seems that although circulating cells are not a major source of regenerating ECs, these cells may regulate EC regeneration and vascular repair through the release of reparative paracrine factors that act on the vascular endothelium.

\section{Future Perspectives}

Improved understanding of the cellular and molecular mechanisms that control the intrinsic endothelial regenerative and reparative processes could lead to the development of novel and effective treatments for diseases characterized by EC injury and dysfunction. As described in this review, multiple transcription factors and signaling pathways that control the intrinsic endothelial regeneration and vascular repair process have been identified (Figures 2 and 3 and Table 1). Although intuitive, it has been convincingly demonstrated that endothelial regeneration is significantly impaired with aging, at least in large vessels. ${ }^{24}$ Additional studies that aim to further dissect the mechanisms of agingimpaired endothelial regeneration and vascular repair and elucidation of potential organ-specific regulation would be of high value. It would be interesting to see which of the reparative factors/pathways summarized in this review are impaired by aging and other risk factors for EC dysfunction and to study whether restoration of their functions could reactivate the intrinsic regenerative process in aged animals and elderly patients after vascular injury. Given the drastic increases in severity and mortality of elderly patients with sepsis and ARDS derived from pneumonia, flu, and coronavirus 19 (COVID-19), this line of research is of high relevance. ${ }^{84-87}$ Future development of small molecule drugs that target regenerative and reparative pathways, such as the GPCR-dependent $\mathrm{p} 110 \gamma \mathrm{PI} 3 \mathrm{~K}$ pathway, and/or development of cell-based gene therapy to activate the regenerative and reparative mechanisms for treatment of vascular diseases is warranted. Indeed, it is important to know whether vadadustat, a HIF prolyl hydroxylase 
inhibitor, is effective to promote recovery and survival of patients with severe COVID-19 (NCT04478071) because it may activate HIF- $1 \alpha$-dependent endothelial regeneration and vascular repair.

The metabolism of ECs in diseased vasculature is markedly aberrant, given that cell proliferation and endothelial junction reannealing are metabolically demanding processes that require substantial energy and biomass. ${ }^{60,88}$ Characterization of EC metabolism in regenerating endothelium is appealing, which could reveal novel reparative pathways and facilitate the targeting of endothelial metabolism in endothelial regeneration and vascular repair. ${ }^{89}$ The potential of modulating epigenetic enzyme activities to accelerate EC recovery and vascular repair remains to be fully explored. The metabolic and epigenetic control of endothelial regeneration and vascular repair after injury therefore represents another area of research that warrants further attention.

Studies could also aim to identify the discrete EC subpopulation(s) with the greatest proliferative potential, for instance, by comparing venous and arterial $\mathrm{ECs}^{90}$ and by studying ECs across different tissue types. ${ }^{91,92}$ One potentially productive approach would be to use single-cell RNAsequencing analysis to define the subpopulations of regenerative ECs or putative tissue-resident vascular endothelial stem/progenitor cells. ${ }^{19,28,93}$ Genetic lineage tracing and genetic depletion approaches could be used to define the roles of specific EC subpopulations in mediating endothelial regeneration. Defining such a regenerative subpopulation of ECs would be a crucial first step for their isolation, expansion, and use in regenerative medicine.

In future studies, the effect of different types of non-ECs, including adult stem/progenitor cells (eg, MSCs), on EC regeneration and vascular repair could also be investigated. Adult stem cells release various paracrine factors, including microparticles/microvesicles and miRNAs, to stimulate endothelial regeneration and vascular repair. ${ }^{76-78}$ SMCs also release multiple reparative factors, such as CXCL1 and CXCL7, that stimulate EC migration ${ }^{83,94}$ or activate regenerative signaling pathways in ECs. ${ }^{44}$ Future studies should aim to elucidate the mechanisms by which exogenous progenitor cells activate the intrinsic regenerative and reparative programs, which could lead to the exploitation of cell-based gene therapy to activate the intrinsic endothelial regeneration and vascular repair processes.

It also remains to be seen whether other vascular cell types, including fibroblasts, could be directly converted into endothelial progenitors or even ECs at the injury sites for in situ endothelial regeneration. The direct conversion of fibroblasts into functional ECs could hold great promise for the inhibition of atherosclerosis and restenosis after endothelial denudation by angioplasty treatment. Although adult stem cells, including MSCs and BM-derived progenitor cells, are rarely engrafted into the damaged vasculature, recent studies have found that induced ECs or EPCs differentiated from embryonic or induced pluripotent stem cells or directly reprogrammed from fibroblasts and other cell types can engraft into local neovasculature of ischemic tissue to improve tissue perfusion. ${ }^{95-97}$ Thus, it would be interesting to determine whether and under what conditions transplantation of induced ECs or EPCs can engraft into injured endothelium for endothelial regeneration and vascular repair. Finally, future studies of the EC response to changes in mechanical flow could be of interest ${ }^{98}$ given that decreased flow can impair endothelial repair ${ }^{99}$ and that the injury and repair phases of vascular conditions, such as restenosis, atherosclerosis, and thrombosis, are characterized by changes in flow forces.

\section{Conclusions}

Endothelial regeneration and vascular repair after vascular injury is predominantly dependent on tissue-resident ECs through migration and proliferation. Future studies should aim to characterize the regenerative EC subpopulation(s), identify intrinsic regenerative and reparative signaling pathways, and develop pharmacologic and/or cell-based gene therapies. These strategies would enable harnessing the intrinsic regenerative and reparative processes for the treatment of vascular disorders characterized by endothelial injury, such as atherosclerosis, restenosis, sepsis, and ARDS, including severe COVID-19.

\section{References}

1. Deanfield JE, Halcox JP, Rabelink TJ: Endothelial function and dysfunction: testing and clinical relevance. Circulation 2007, 115: $1285-1295$

2. Cines DB, Pollak ES, Buck CA, Loscalzo J, Zimmerman GA, McEver RP, Pober JS, Wick TM, Konkle BA, Schwartz BS, Barnathan ES, McCrae KR, Hug BA, Schmidt AM, Stern DM: Endothelial cells in physiology and in the pathophysiology of vascular disorders. Blood 1998, 91:3527-3561

3. Libby P, Ridker PM, Maseri A: Inflammation and atherosclerosis. Circulation 2002, 105:1135-1143

4. Aird WC: The role of the endothelium in severe sepsis and multiple organ dysfunction syndrome. Blood 2003, 101:3765-3777

5. De Backer D, Creteur J, Preiser JC, Dubois MJ, Vincent JL: Microvascular blood flow is altered in patients with sepsis. Am J Respir Crit Care Med 2002, 166:98-104

6. Goldenberg NM, Steinberg BE, Slutsky AS, Lee WL: Broken barriers: a new take on sepsis pathogenesis. Sci Transl Med 2011, 3: $88 \mathrm{ps} 25$

7. Mirza MK, Sun Y, Zhao YD, Potula HH, Frey RS, Vogel SM Malik AB, Zhao YY: FoxM1 regulates re-annealing of endothelial adherens junctions through transcriptional control of beta-catenin expression. J Exp Med 2010, 207:1675-1685

8. Sakr Y, Dubois MJ, De Backer D, Creteur J, Vincent JL: Persistent microcirculatory alterations are associated with organ failure and death in patients with septic shock. Crit Care Med 2004, 32: $1825-1831$

9. Zhao YY, Gao XP, Zhao YD, Mirza MK, Frey RS, Kalinichenko VV, Wang IC, Costa RH, Malik AB: Endothelial cell-restricted disruption of FoxM1 impairs endothelial repair following LPS-induced vascular injury. J Clin Invest 2006, 116:2333-2343

10. Huang X, Dai Z, Cai L, Sun K, Cho J, Albertine KH, Malik AB, Schraufnagel DE, Zhao YY: Endothelial p110gammaPI3K mediates 
endothelial regeneration and vascular repair after inflammatory vascular injury. Circulation 2016, 133:1093-1103

11. Komarova YA, Kruse K, Mehta D, Malik AB: Protein interactions at endothelial junctions and signaling mechanisms regulating endothelial permeability. Circ Res 2017, 120:179-206

12. Asahara T, Murohara T, Sullivan A, Silver M, van der Zee R, Li T, Witzenbichler B, Schatteman G, Isner JM: Isolation of putative progenitor endothelial cells for angiogenesis. Science 1997, 275: 964-967

13. Isner JM, Kalka C, Kawamoto A, Asahara T: Bone marrow as a source of endothelial cells for natural and iatrogenic vascular repair. Ann N Y Acad Sci 2001, 953:75-84

14. Walter DH, Rittig K, Bahlmann FH, Kirchmair R, Silver M, Murayama T, Nishimura H, Losordo DW, Asahara T, Isner JM: Statin therapy accelerates reendothelialization: a novel effect involving mobilization and incorporation of bone marrow-derived endothelial progenitor cells. Circulation 2002, 105:3017-3024

15. Walter DH, Haendeler J, Reinhold J, Rochwalsky U, Seeger F, Honold J, Hoffmann J, Urbich C, Lehmann R, ArenzanaSeisdesdos F, Aicher A, Heeschen C, Fichtlscherer S, Zeiher AM, Dimmeler S: Impaired CXCR4 signaling contributes to the reduced neovascularization capacity of endothelial progenitor cells from patients with coronary artery disease. Circ Res 2005, 97:1142-1151

16. Bautch VL: Stem cells and the vasculature. Nat Med 2011, 17: $1437-1443$

17. Medina RJ, Barber CL, Sabatier F, Dignat-George F, MeleroMartin JM, Khosrotehrani K, Ohneda O, Randi AM, Chan JKY, Yamaguchi T, Van Hinsbergh VWM, Yoder MC, Stitt AW: Endothelial progenitors: a consensus statement on nomenclature. Stem Cells Transl Med 2017, 6:1316-1320

18. Ohle SJ, Anandaiah A, Fabian AJ, Fine A, Kotton DN: Maintenance and repair of the lung endothelium does not involve contributions from marrow-derived endothelial precursor cells. Am J Respir Cell Mol Biol 2012, 47:11-19

19. Kawasaki T, Nishiwaki T, Sekine A, Nishimura R, Suda R, Urushibara T, Suzuki T, Takayanagi S, Terada J, Sakao S, Tatsumi K: Vascular repair by tissue-resident endothelial progenitor cells in endotoxin-induced lung injury. Am J Respir Cell Mol Biol 2015, 53: $500-512$

20. Hagensen MK, Raarup MK, Mortensen MB, Thim T, Nyengaard JR, Falk E, Bentzon JF: Circulating endothelial progenitor cells do not contribute to regeneration of endothelium after murine arterial injury. Cardiovasc Res 2012, 93:223-231

21. Purhonen S, Palm J, Rossi D, Kaskenpaa N, Rajantie I, YlaHerttuala S, Alitalo K, Weissman IL, Salven P: Bone marrow-derived circulating endothelial precursors do not contribute to vascular endothelium and are not needed for tumor growth. Proc Natl Acad Sci U S A 2008, 105:6620-6625

22. Singhal M, Liu X, Inverso D, Jiang K, Dai J, He H, Bartels S, Li W, Abdul Pari AA, Gengenbacher N, Besemfelder E, Hui L, Augustin HG, Hu J: Endothelial cell fitness dictates the source of regenerating liver vasculature. J Exp Med 2018, 215:2497-2508

23. Itoh Y, Toriumi H, Yamada S, Hoshino H, Suzuki N: Resident endothelial cells surrounding damaged arterial endothelium reendothelialize the lesion. Arterioscler Thromb Vasc Biol 2010, 30:1725-1732

24. McDonald AI, Shirali AS, Aragon R, Ma F, Hernandez G, Vaughn DA, Mack JJ, Lim TY, Sunshine H, Zhao P, Kalinichenko V, Hai T, Pelegrini M, Ardehali R, Iruela-Arispe ML: Endothelial regeneration of large vessels is a biphasic process driven by local cells with distinct proliferative capacities. Cell Stem Cell 2018, 23: 210-225 e6

25. Liu M, Zhang L, Marsboom G, Jambusaria A, Xiong S, Toth PT, Benevolenskaya EV, Rehman J, Malik AB: Sox17 is required for endothelial regeneration following inflammation-induced vascular injury. Nat Commun 2019, 10:2126

26. Nolan DJ, Ginsberg M, Israely E, Palikuqi B, Poulos MG, James D, Ding BS, Schachterle W, Liu Y, Rosenwaks Z, Butler JM, Xiang J,
Rafii A, Shido K, Rabbany SY, Elemento O, Rafii S: Molecular signatures of tissue-specific microvascular endothelial cell heterogeneity in organ maintenance and regeneration. Dev Cell 2013, 26:204-219

27. Marcu R, Choi YJ, Xue J, Fortin CL, Wang Y, Nagao RJ, Xu J, MacDonald JW, Bammler TK, Murry CE, Muczynski K, Stevens KR, Himmelfarb J, Schwartz SM, Zheng Y: Human organspecific endothelial cell heterogeneity. iScience 2018, 4:20-35

28. Wakabayashi T, Naito H, Suehiro JI, Lin Y, Kawaji H, Iba T, Kouno T, Ishikawa-Kato S, Furuno M, Takara K, Muramatsu F, Weizhen J, Kidoya H, Ishihara K, Hayashizaki Y, Nishida K, Yoder MC, Takakura N: CD157 marks tissue-resident endothelial stem cells with homeostatic and regenerative properties. Cell Stem Cell 2018, 22:384-397.e6

29. Slukvin II, Kumar A: The mesenchymoangioblast, mesodermal precursor for mesenchymal and endothelial cells. Cell Mol Life Sci 2018, 75:3507-3520

30. Iwasaki M, Koyanagi M, Kossmann H, Monsefi N, Rupp S, Trauth J, Paulus P, Goetz R, Momma S, Tjwa M, Ohtani K, Henschler R, Schranz D, Cossu G, Zacharowski K, Martens S, Zeiher AM, Dimmeler S: Hepatocyte growth factor mobilizes non-bone marrowderived circulating mesoangioblasts. Eur Heart J 2011, 32:627-636

31. Laurenzana A, Cencetti F, Serrati S, Bruno G, Japtok L, Bianchini F, Torre E, Fibbi G, Del Rosso M, Bruni P, Donati C: Endothelial sphingosine kinase/SPNS2 axis is critical for vessel-like formation by human mesoangioblasts. J Mol Med (Berlin) 2015, 93:1145-1157

32. Galli D, Innocenzi A, Staszewsky L, Zanetta L, Sampaolesi M, Bai A, Martinoli E, Carlo E, Balconi G, Fiordaliso F, Chimenti S, Cusella G, Dejana E, Cossu G, Latini R: Mesoangioblasts, vessel-associated multipotent stem cells, repair the infarcted heart by multiple cellular mechanisms: a comparison with bone marrow progenitors, fibroblasts, and endothelial cells. Arterioscler Thromb Vasc Biol 2005, 25: 692-697

33. Kaestner KH, Knochel W, Martinez DE: Unified nomenclature for the winged helix/forkhead transcription factors. Genes Dev 2000, 14: $142-146$

34. Huang X, Zhao YY: Transgenic expression of FoxM1 promotes endothelial repair following lung injury induced by polymicrobial sepsis in mice. PLoS One 2012, 7:e50094

35. Ratcliffe P, Koivunen P, Myllyharju J, Ragoussis J, Bovee JV, Batinic-Haberle I, Vinatier C, Trichet V, Robriquet F, Oliver L, Gardie B: Update on hypoxia-inducible factors and hydroxylases in oxygen regulatory pathways: from physiology to therapeutics. Нypoxia $2017,5: 11-20$

36. Ratcliffe PJ: HIF-1 and HIF-2: working alone or together in hypoxia? J Clin Invest 2007, 117:862-865

37. Huang X, Zhang X, Zhao DX, Yin J, Hu G, Evans CE, Zhao YY: Endothelial hypoxia-inducible factor-1alpha is required for vascular repair and resolution of inflammatory lung injury through forkhead box protein M1. Am J Pathol 2019, 189:1664-1679

38. Nakajima-Takagi Y, Osawa M, Oshima M, Takagi H, Miyagi S, Endoh M, Endo TA, Takayama N, Eto K, Toyoda T, Koseki H, Nakauchi H, Iwama A: Role of SOX17 in hematopoietic development from human embryonic stem cells. Blood 2013, 121:447-458

39. Gold ES, Ramsey SA, Sartain MJ, Selinummi J, Podolsky I, Rodriguez DJ, Moritz RL, Aderem A: ATF3 protects against atherosclerosis by suppressing 25-hydroxycholesterol-induced lipid body formation. J Exp Med 2012, 209:807-817

40. Wu X, Nguyen BC, Dziunycz P, Chang S, Brooks Y, Lefort K, Hofbauer GF, Dotto GP: Opposing roles for calcineurin and ATF3 in squamous skin cancer. Nature 2010, 465:368-372

41. Schober A, Nazari-Jahantigh M, Wei Y, Bidzhekov K, Gremse F, Grommes J, Megens RT, Heyll K, Noels H, Hristov M, Wang S, Kiessling F, Olson EN, Weber C: MicroRNA-126-5p promotes endothelial proliferation and limits atherosclerosis by suppressing Dlk1. Nat Med 2014, 20:368-376

42. Jansen F, Yang X, Hoelscher M, Cattelan A, Schmitz T, Proebsting S, Wenzel D, Vosen S, Franklin BS, Fleischmann BK, Nickenig G, 
Werner N: Endothelial microparticle-mediated transfer of microRNA126 promotes vascular endothelial cell repair via SPRED1 and is abrogated in glucose-damaged endothelial microparticles. Circulation 2013, 128:2026-2038

43. Wang S, Aurora AB, Johnson BA, Qi X, McAnally J, Hill JA, Richardson JA, Bassel-Duby R, Olson EN: The endothelial-specific microRNA miR-126 governs vascular integrity and angiogenesis. Dev Cell 2008, 15:261-271

44. Miyagawa K, Shi M, Chen PI, Hennigs JK, Zhao Z, Wang M, Li CG, Saito T, Taylor S, Sa S, Cao A, Wang L, Snyder MP, Rabinovitch M: Smooth muscle contact drives endothelial regeneration by BMPR2notch1-mediated metabolic and epigenetic changes. Circ Res 2019, $124: 211-224$

45. Masoud AG, Lin J, Azad AK, Farhan MA, Fischer C, Zhu LF, Zhang H, Sis B, Kassiri Z, Moore RB, Kim D, Anderson CC, Vederas JC, Adam BA, Oudit GY, Murray AG: Apelin directs endothelial cell differentiation and vascular repair following immunemediated injury. J Clin Invest 2020, 130:94-107

46. Eyries M, Siegfried G, Ciumas M, Montagne K, Agrapart M, Lebrin F, Soubrier F: Hypoxia-induced apelin expression regulates endothelial cell proliferation and regenerative angiogenesis. Circ Res 2008, 103:432-440

47. Ostendorf T, Kunter U, Eitner F, Loos A, Regele H, Kerjaschki D, Henninger DD, Janjic N, Floege J: VEGF(165) mediates glomerular endothelial repair. J Clin Invest 1999, 104:913-923

48. Callow AD, Choi ET, Trachtenberg JD, Stevens SL, Connolly DT, Rodi C, Ryan US: Vascular permeability factor accelerates endothelial regrowth following balloon angioplasty. Growth Factors 1994, $10: 223-228$

49. Buchwald AB, Kunze C, Waltenberger J, Unterberg-Buchwald C: Transfection of the DNA for the receptor KDR/flk-1 attenuates neointimal proliferation and luminal narrowing in a coronary stent angioplasty model. J Surg Res 2006, 136:120-124

50. Hutter R, Carrick FE, Valdiviezo C, Wolinsky C, Rudge JS, Wiegand SJ, Fuster V, Badimon JJ, Sauter BV: Vascular endothelial growth factor regulates reendothelialization and neointima formation in a mouse model of arterial injury. Circulation 2004, 110: $2430-2435$

51. Imrie H, Viswambharan H, Sukumar P, Abbas A, Cubbon RM, Yuldasheva N, Gage M, Smith J, Galloway S, Skromna A, Rashid ST, Futers TS, Xuan S, Gatenby VK, Grant PJ, Channon KM, Beech DJ, Wheatcroft SB, Kearney MT: Novel role of the IGF-1 receptor in endothelial function and repair: studies in endotheliumtargeted IGF-1 receptor transgenic mice. Diabetes 2012, 61: 2359-2368

52. Konishi H, Sydow K, Cooke JP: Dimethylarginine dimethylaminohydrolase promotes endothelial repair after vascular injury. J Am Coll Cardiol 2007, 49:1099-1105

53. Giannotta M, Trani M, Dejana E: VE-cadherin and endothelial adherens junctions: active guardians of vascular integrity. Dev Cell 2013, 26:441-454

54. Kruse K, Lee QS, Sun Y, Klomp J, Yang X, Huang F, Sun MY, Zhao S, Hong Z, Vogel SM, Shin JW, Leckband DE, Tai LM, Malik AB, Komarova YA: N-cadherin signaling via Trio assembles adherens junctions to restrict endothelial permeability. J Cell Biol 2019, 218:299-316

55. Timmerman I, Hoogenboezem M, Bennett AM, Geerts D, Hordijk PL, van Buul JD: The tyrosine phosphatase SHP2 regulates recovery of endothelial adherens junctions through control of betacatenin phosphorylation. Mol Biol Cell 2012, 23:4212-4225

56. Knezevic N, Tauseef M, Thennes T, Mehta D: The G protein betagamma subunit mediates reannealing of adherens junctions to reverse endothelial permeability increase by thrombin. J Exp Med 2009, 206: $2761-2777$

57. Creighton J, Jian M, Sayner S, Alexeyev M, Insel PA: Adenosine monophosphate-activated kinase alpha1 promotes endothelial barrier repair. FASEB J 2011, 25:3356-3365
58. Jian MY, Alexeyev MF, Wolkowicz PE, Zmijewski JW, Creighton JR: Metformin-stimulated AMPK-alphal promotes microvascular repair in acute lung injury. Am J Physiol Lung Cell Mol Physiol 2013, 305:L844-L855

59. Jian MY, Liu Y, Li Q, Wolkowicz P, Alexeyev M, Zmijewski J, Creighton J: N-cadherin coordinates AMP kinase-mediated lung vascular repair. Am J Physiol Lung Cell Mol Physiol 2016, 310: L71-L85

60. Cheung KCP, Fanti S, Mauro C, Wang G, Nair AS, Fu H, Angeletti S, Spoto S, Fogolari M, Romano F, Aksentijevic D, Liu W, Li B, Cheng L, Jiang L, Vuononvirta J, Poobalasingam TR, Smith DM, Ciccozzi M, Solito E, Marelli-Berg FM: Preservation of microvascular barrier function requires $\mathrm{CD} 31$ receptor-induced metabolic reprogramming. Nat Commun 2020, 11:3595

61. Fu P, Ramchandran R, Shaaya M, Huang L, Ebenezer DL, Jiang Y, Komarova Y, Vogel SM, Malik AB, Minshall RD, Du G, Tonks NK, Natarajan V: Phospholipase D2 restores endothelial barrier function by promoting PTPN14-mediated VE-cadherin dephosphorylation. J Biol Chem 2020, 295:7669-7685

62. Rajput C, Tauseef M, Farazuddin M, Yazbeck P, Amin MR, Avin Br V, Sharma T, Mehta D: MicroRNA-150 suppression of angiopoetin-2 generation and signaling is crucial for resolving vascular injury. Arterioscler Thromb Vasc Biol 2016, 36: 380-388

63. Ghani U, Shuaib A, Salam A, Nasir A, Shuaib U, Jeerakathil T, Sher F, O'Rourke F, Nasser AM, Schwindt B, Todd K: Endothelial progenitor cells during cerebrovascular disease. Stroke 2005, 36: $151-153$

64. Rafat N, Tonshoff B, Bierhaus A, Beck GC: Endothelial progenitor cells in regeneration after acute lung injury: do they play a role? Am J Respir Cell Mol Biol 2013, 48:399-405

65. Wary KK, Vogel SM, Garrean S, Zhao YD, Malik AB: Requirement of alpha(4)beta(1) and alpha(5)beta(1) integrin expression in bonemarrow-derived progenitor cells in preventing endotoxin-induced lung vascular injury and edema in mice. Stem Cells 2009, 27: $3112-3120$

66. Zhao YD, Ohkawara H, Vogel SM, Malik AB, Zhao YY: Bone marrow-derived progenitor cells prevent thrombin-induced increase in lung vascular permeability. Am J Physiol Lung Cell Mol Physiol 2010, 298:L36-L44

67. Gupta N, Su X, Popov B, Lee JW, Serikov V, Matthay MA: Intrapulmonary delivery of bone marrow-derived mesenchymal stem cells improves survival and attenuates endotoxin-induced acute lung injury in mice. J Immunol 2007, 179:1855-1863

68. Mei SH, Haitsma JJ, Dos Santos CC, Deng Y, Lai PF, Slutsky AS, Liles WC, Stewart DJ: Mesenchymal stem cells reduce inflammation while enhancing bacterial clearance and improving survival in sepsis. Am J Respir Crit Care Med 2010, 182:1047-1057

69. Nemeth K, Leelahavanichkul A, Yuen PS, Mayer B, Parmelee A, Doi K, Robey PG, Leelahavanichkul K, Koller BH, Brown JM, Hu X, Jelinek I, Star RA, Mezey E: Bone marrow stromal cells attenuate sepsis via prostaglandin E(2)-dependent reprogramming of host macrophages to increase their interleukin-10 production. Nat Med 2009, 15:42-49

70. Lee JW, Fang X, Gupta N, Serikov V, Matthay MA: Allogeneic human mesenchymal stem cells for treatment of E. coli endotoxininduced acute lung injury in the ex vivo perfused human lung. Proc Natl Acad Sci U S A 2009, 106:16357-16362

71. Lee JW, Krasnodembskaya A, McKenna DH, Song Y, Abbott J, Matthay MA: Therapeutic effects of human mesenchymal stem cells in ex vivo human lungs injured with live bacteria. Am J Respir Crit Care Med 2013, 187:751-760

72. Zhao YD, Ohkawara H, Rehman J, Wary KK, Vogel SM, Minshall RD, Zhao YY, Malik AB: Bone marrow progenitor cells induce endothelial adherens junction integrity by sphingosine-1phosphate-mediated Rac1 and Cdc42 signaling. Circ Res 2009, 105:696-704 
73. Matthay MA, Calfee CS, Zhuo H, Thompson BT, Wilson JG, Levitt JE, Rogers AJ, Gotts JE, Wiener-Kronish JP, Bajwa EK, Donahoe MP, McVerry BJ, Ortiz LA, Exline M, Christman JW, Abbott J, Delucchi KL, Caballero L, McMillan M, McKenna DH, Liu KD: Treatment with allogeneic mesenchymal stromal cells for moderate to severe acute respiratory distress syndrome (START study): a randomised phase 2a safety trial. Lancet Respir Med 2019, $7: 154-162$

74. Huppert LA, Liu KD, Matthay MA: Therapeutic potential of mesenchymal stromal cells in the treatment of ARDS. Transfusion 2019, 59:869-875

75. Zhao YD, Huang X, Yi F, Dai Z, Qian Z, Tiruppathi C, Tran K, Zhao YY: Endothelial FoxM1 mediates bone marrow progenitor cellinduced vascular repair and resolution of inflammation following inflammatory lung injury. Stem Cells 2014, 32:1855-1864

76. Schinkothe T, Bloch $\mathrm{W}$, Schmidt A: In vitro secreting profile of human mesenchymal stem cells. Stem Cells Dev 2008, 17:199-206

77. Ionescu L, Byrne RN, van Haaften T, Vadivel A, Alphonse RS, ReyParra GJ, Weissmann G, Hall A, Eaton F, Thebaud B: Stem cell conditioned medium improves acute lung injury in mice: in vivo evidence for stem cell paracrine action. Am J Physiol Lung Cell Mol Physiol 2012, 303:L967-L977

78. Ranganath SH, Levy O, Inamdar MS, Karp JM: Harnessing the mesenchymal stem cell secretome for the treatment of cardiovascular disease. Cell Stem Cell 2012, 10:244-258

79. Dignat-George F, Boulanger CM: The many faces of endothelial microparticles. Arterioscler Thromb Vasc Biol 2011, 31:27-33

80. Deregibus MC, Cantaluppi V, Calogero R, Lo Iacono M, Tetta C, Biancone L, Bruno S, Bussolati B, Camussi G: Endothelial progenitor cell derived microvesicles activate an angiogenic program in endothelial cells by a horizontal transfer of mRNA. Blood 2007, 110: $2440-2448$

81. Morel O, Toti F, Morel N, Freyssinet JM: Microparticles in endothelial cell and vascular homeostasis: are they really noxious? Haematologica 2009, 94:313-317

82. Leroyer AS, Rautou PE, Silvestre JS, Castier Y, Leseche G, Devue C, Duriez M, Brandes RP, Lutgens E, Tedgui A, Boulanger CM: CD40 ligand + microparticles from human atherosclerotic plaques stimulate endothelial proliferation and angiogenesis a potential mechanism for intraplaque neovascularization. J Am Coll Cardiol 2008, 52: $1302-1311$

83. Ren J, Zhou T, Pilli VSS, Phan N, Wang Q, Gupta K, Liu Z, Sheibani N, Liu B: Novel paracrine functions of smooth muscle cells in supporting endothelial regeneration following arterial injury. Circ Res 2019, 124:1253-1265

84. Ross MD: Endothelial regenerative capacity and aging: influence of diet, exercise and obesity. Curr Cardiol Rev 2018, 14:233-244

85. Torella D, Leosco D, Indolfi C, Curcio A, Coppola C, Ellison GM, Russo VG, Torella M, Li Volti G, Rengo F, Chiariello M: Aging exacerbates negative remodeling and impairs endothelial regeneration after balloon injury. Am J Physiol Heart Circ Physiol 2004, 287: $\mathrm{H} 2850-\mathrm{H} 2860$

86. Sandri M, Viehmann M, Adams V, Rabald K, Mangner N, Hollriegel R, Lurz P, Erbs S, Linke A, Kirsch K, Mobius-Winkler S,
Thiery J, Teupser D, Hambrecht R, Schuler G, Gielen S: Chronic heart failure and aging - effects of exercise training on endothelial function and mechanisms of endothelial regeneration: results from the Leipzig Exercise Intervention in Chronic heart failure and Aging (LEICA) study. Eur J Prev Cardiol 2016, 23:349-358

87. Zhang Y, Herbert BS, Rajashekhar G, Ingram DA, Yoder MC, Clauss M, Rehman J: Premature senescence of highly proliferative endothelial progenitor cells is induced by tumor necrosis factor-alpha via the p38 mitogen-activated protein kinase pathway. FASEB J 2009, 23:1358-1365

88. Kalucka J, Missiaen R, Georgiadou M, Schoors S, Lange C, De Bock K, Dewerchin M, Carmeliet P: Metabolic control of the cell cycle. Cell Cycle 2015, 14:3379-3388

89. Bierhansl L, Conradi LC, Treps L, Dewerchin M, Carmeliet P: Central role of metabolism in endothelial cell function and vascular disease. Physiology (Bethesda) 2017, 32:126-140

90. Xu C, Hasan SS, Schmidt I, Rocha SF, Pitulescu ME, Bussmann J, Meyen D, Raz E, Adams RH, Siekmann AF: Arteries are formed by vein-derived endothelial tip cells. Nat Commun 2014, 5:5758

91. Ingram DA, Mead LE, Moore DB, Woodard W, Fenoglio A, Yoder MC: Vessel wall-derived endothelial cells rapidly proliferate because they contain a complete hierarchy of endothelial progenitor cells. Blood 2005, 105:2783-2786

92. Patel J, Seppanen EJ, Rodero MP, Wong HY, Donovan P, Neufeld Z, Fisk NM, Francois M, Khosrotehrani K: Functional definition of progenitors versus mature endothelial cells reveals key soxfdependent differentiation process. Circulation 2017, 135:786-805

93. Fang S, Wei J, Pentinmikko N, Leinonen H, Salven P: Generation of functional blood vessels from a single c-kit + adult vascular endothelial stem cell. PLoS Biol 2012, 10:e1001407

94. Yu B, Wong MM, Potter CM, Simpson RM, Karamariti E, Zhang Z, Zeng L, Warren D, Hu Y, Wang W, Xu Q: Vascular stem/progenitor cell migration induced by smooth muscle cell-derived chemokine (C$\mathrm{C}$ motif) ligand 2 and chemokine (C-X-C motif) ligand 1 contributes to neointima formation. Stem Cells 2016, 34:2368-2380

95. Han JK, Chang SH, Cho HJ, Choi SB, Ahn HS, Lee J, Jeong H, Youn SW, Lee HJ, Kwon YW, Cho HJ, Oh BH, Oettgen P, Park YB, Kim HS: Direct conversion of adult skin fibroblasts to endothelial cells by defined factors. Circulation 2014, 130:1168-1178

96. Morita R, Suzuki M, Kasahara H, Shimizu N, Shichita T, Sekiya T, Kimura A, Sasaki K, Yasukawa H, Yoshimura A: ETS transcription factor ETV2 directly converts human fibroblasts into functional endothelial cells. Proc Natl Acad Sci U S A 2015, 112:160-165

97. Margariti A, Winkler B, Karamariti E, Zampetaki A, Tsai TN, Baban D, Ragoussis J, Huang Y, Han JD, Zeng L, Hu Y, Xu Q: Direct reprogramming of fibroblasts into endothelial cells capable of angiogenesis and reendothelialization in tissue-engineered vessels. Proc Natl Acad Sci U S A 2012, 109:13793-13798

98. Van der Heiden K, Gijsen FJ, Narracott A, Hsiao S, Halliday I, Gunn J, Wentzel JJ, Evans PC: The effects of stenting on shear stress: relevance to endothelial injury and repair. Cardiovasc Res 2013, 99: 269-275

99. Vyalov S, Langille BL, Gotlieb AI: Decreased blood flow rate disrupts endothelial repair in vivo. Am J Pathol 1996, 149:2107-2118 